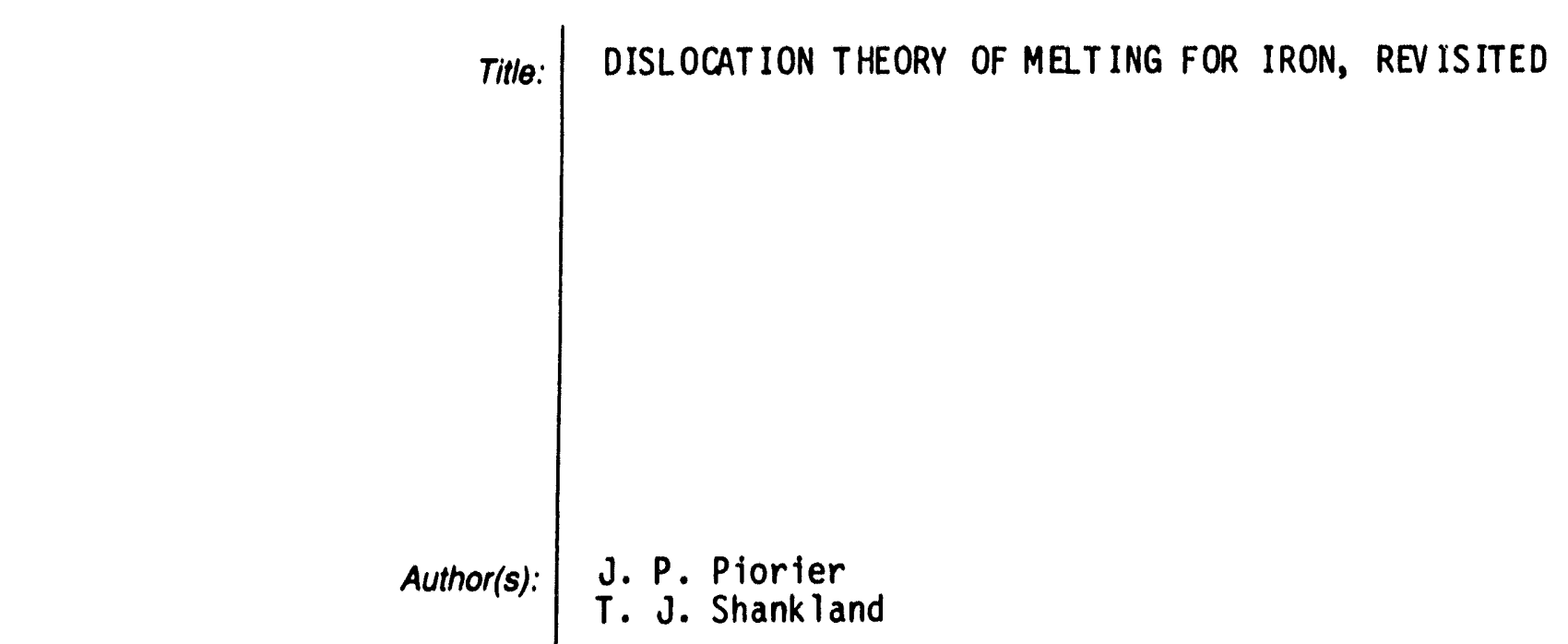

Submitted to: 1993 JOINT AIRAPT /APS CONFERENCE COLORADO SPRINGS, CO June 1993

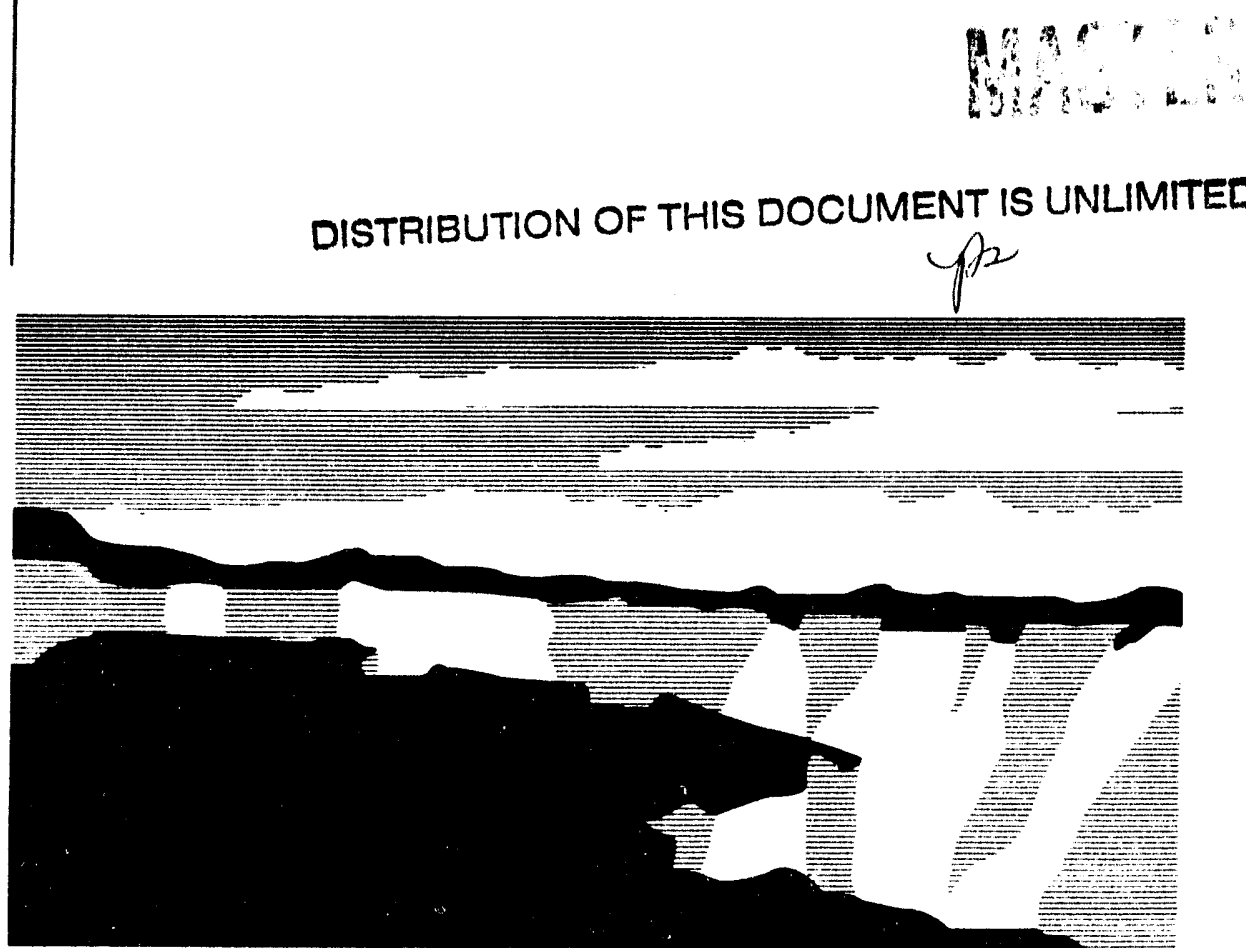

Los Alamos National Laboratory, an affirmative actionequal oppontunity employer, is operated by the University of California for the U.S. Department of Energy under contract W.7405-ENG.36. By acceptance of this article, the publisher recognizes that the U.S. Government retains a nonexclusive, royalty-free license to publish or reproduce the published form of this contribution, or to allow others to do so, for U.S. Government purposes. The Los Alamos National Laboratory requests that the publisher identity this anticle as work performed under the auspices of the U.S. Department of Energy. 


\title{
DISLOCATION THEORY OF MELTING FOR IRON, REVISITED
}

\author{
J.-P.Poirier, \\ Département des Géomatériaux \\ Institut de Physique du Globe de Paris \\ 75252 Paris Cedex 05 \\ FRANCE \\ T. J. Shankland \\ Earth and Environmental Sciences Division,MS D443 \\ Los Alamos National Laboratory \\ Los Alamos, New Mexico 84545 \\ USA
}

The melting point $T_{m}$ of iron at conditions of the Earth's inner core boundary (ICB) has been calculated from the dislocation theory of melting in metals. Monte Carlo calculations were used to estimate uncertainties introduced by uncertainty in the geophvsical parameters that are used in the calculations. These calculations take into account the effects of pressure at ICB conditions and of possible freezing point depression resulting from dilution of pure iron in the outer core. With this approach $\mathrm{T}_{\mathrm{m}}$ of pure $\varepsilon$-Fe at a pressure of $330 \mathrm{GPa}$ and without freezing point depression is $6160 \pm 250 \mathrm{~K}$; for a $1000 \mathrm{~K}$ freezing point depression it is $6110 \mathrm{~K}$. $\mathrm{T}_{\mathrm{m}}$ of pure $\gamma-\mathrm{Fe}$ is $6060 \mathrm{~K}$, a value that is not significantly different. A possible $\alpha^{\prime}$ phase would melt at $5600 \mathrm{~K}$. These values agree with calculated shock wave determinations of $\mathrm{T}_{\mathrm{m}}$. Although calculated $T_{m}$ of the pure phase is little affected by assumptions about the extent of freezing point depression, the estimated temperature of the inner core boundary is lower by the freezing point depression, perhaps $500-1000 \mathrm{~K}$ less than $T_{m}$ of a pure phase.

\section{INTRODUCTION}

In earlier work Poirier [1] calculated the melting temperature $T_{m}$ of iron at ambient pressure using a dislocation melting theory, and found it to be in good agreement with the observed value. This theory is based on the assumption that a melt can be considered as a crystal saturated with dislocations so that it loses long range order. The melting temperature is that for which dislocations can spontaneously nucleate in the solid, i.e., it is the temperature for which the free energy of the crystal saturated with dislocations is equal to that of the dislocation-free crystal. The calculated $T_{m}$ depends on the dislocation concentration at saturation and on an entropic disorder term. When these terms were derived from a fit of calculated quantities to observed values of the fusion volume and entropy good agreement was obtained between calculated and observed values of $T_{m}$ for twelve metals in addition to iron [2].

The calculated melting temperature depends on only three physical parameters: Grüneisen parameter $\gamma$, shear modulus $\mu$, and bulk modulus $\mathrm{K}$ at the temperature and pressure of melting, which are needed at high temperatures and pressures. Seismological Earth models can provide values of $\mu$ and $K$ at the depth of the inner core boundary (ICB), and geophysically estimated values of the Grüneisen parameter can be found in the literature. Using these values, and the hypothesis that the inner core is iron, Poirier [1] estimated a melting temperature of iron at the pressure $\mathrm{P}_{1 \mathrm{CB}}$ of about $6200 \mathrm{~K}$.

The present paper summarizes a refinement [3] of the calculation of the melting point of iron at the pressure of the ICB in three crystal structures that have been suggested for iron in the inner core: $\gamma$ (fcc) $[4], \varepsilon$ (hcp) $[5,6,7]$, 
Anderson 1986, Jeanloz 1990), and $\alpha^{\prime}$, a hypothetical bcc phase theoretically predicted to exist at ICB conditions [8]. We improve on earlier work by equating the Gibbs free energies (appropriate at high pressure) of the dislocationfree and dislocation-saturated crystal instead of Helmholtz free energies. Instead of taking the temperature $T_{I C B}$ at the ICB to be the melting temperature of the inner core material, we more properly use it as the freezing temperature of the outer core; values of the elastic moduli given by seismological models at the ICB are therefore corrected by taking into account possible freezing point depression. These steps more reliably estimate the temperature at the $\mathrm{ICB}$, and inclusion of uncertainties in the geophysical parameters used provides a realistic assessment of errors.

\section{APPROACH}

This section outlines a more detailed presentation given elsewhere $[3]$. During melting the work done by the volume change upon melting $\Delta V_{m}$ against the pressure $P$ is equal to $P \Delta V_{m}$, and the variation in Gibbs free energy between dislocation-saturated liquid and dislocation-free solid is taken to be zero at the melting point. For a melting entropy $\Delta S_{m}$ melting temperature is given by:

$$
T_{m} \Delta S_{m}=\frac{\Delta V_{m} K\lfloor\mid-\varepsilon(\gamma-1 / 3)\rfloor}{2(\gamma-1 / 3)}+P \Delta V_{m}
$$

Here $V$ is molar volume and $\varepsilon$ is the anharmonic dilation:

$$
\varepsilon=\mathrm{A} \frac{\mu}{K}(\gamma-1 / 3) \mathrm{C},
$$

which is given in terms of the saturation concentration of dislocations $C(\approx 0.34)$ and a geometrical coefficient $A$ that depends on crystal structure. $\quad(A=0.225,0.207$ for face-centered cubic and body-centered cubic metals, respectively, and $A=0.229$ for hexagonal closepacked iron with a c/a ratio of 1.6.)

We performed the calculations using a Monte Carlo method in which geophysical parameters needed for the calculation are assigned random values within bands having reasonable uncertainties. The purpose of this approach is to gain a sense of the significance of calculated $T_{m}$ in the face of uncertainties about material properties at the extreme conditions prevailing in the inner core. Uncertainties in parameters of the melting theory such as $\mathrm{C}$ appear directly as errors in calculated temperature. Because of this proportionality to the main parameters of the theory they are treated explicitly rather than as random variables with the understanding that should their values be improved, the calculated $\mathrm{T}_{\mathrm{m}}$ would be changed proportionately.

\section{RESULTS AND DISCUSSION}

Figure 1 shows histograms of calculated melting points for $\varepsilon$ - and $\alpha^{\prime}-F e$. Figure 2 shows
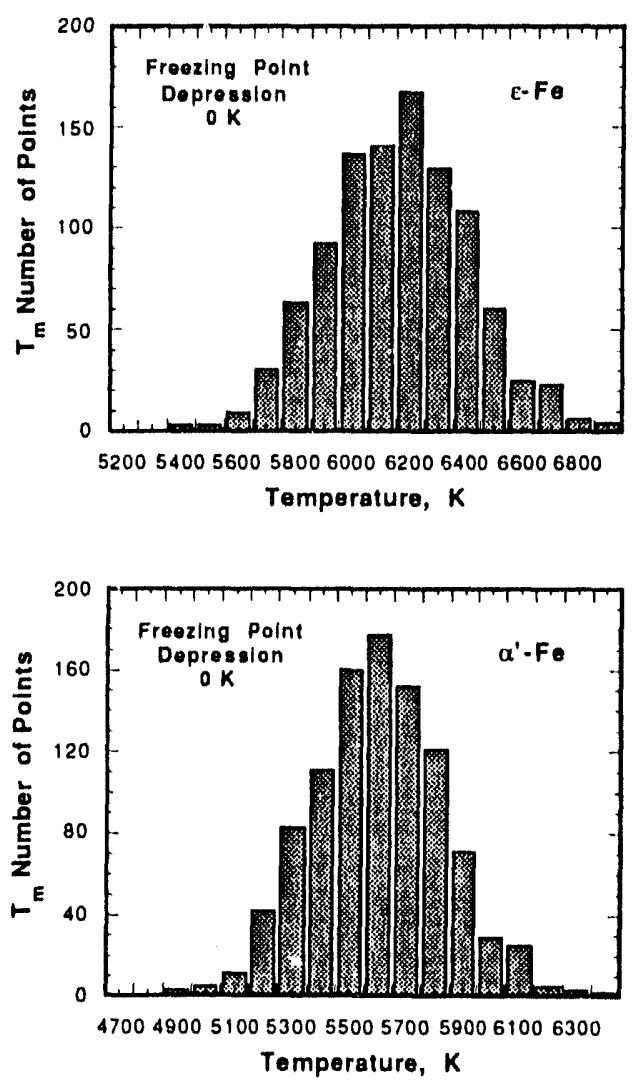

Figure 1. Histogram of calculated melting points of $\varepsilon-F e$ and $\alpha^{\prime}-\mathrm{Fe}$ from 1000 random trials with no freezing point depression. 


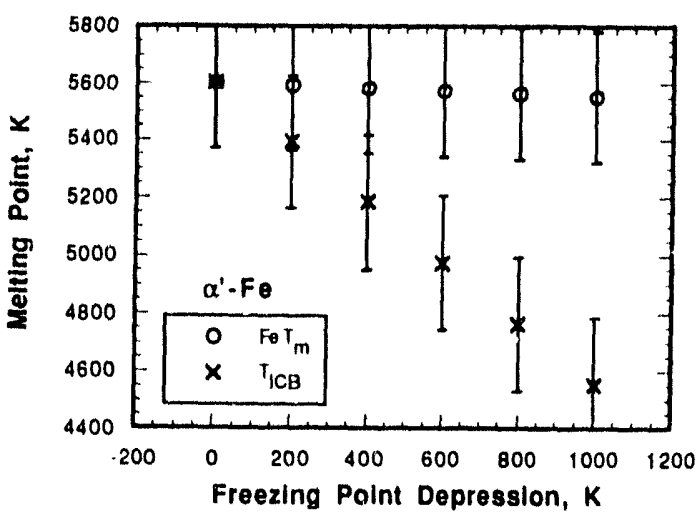

Figure 2. Calculated $T_{m}$ of $\alpha^{\prime}$-iron as a function of freezing point depression. Upper curve is that of iron, and lower curve is that for inner core material having the indicated freezing point depression.

a plot of $T_{m}$ as function of possible freezing point depression at the ICB. The upper curve gives the predicted melting temperature of pure iron as a function of freezing point depression of Fe alloyed with a lighter element. Error bars indicate one standard deviation from the mean. The calculated melting temperature of pure $\mathrm{Fe}$ decreases systematically with increasing freezing point depression because the absolute value of the correction to PREM elastic moduli at the ICB increases; however, the effect is small in comparison with greater uncertainties indicated by the error bars. The lower curve is derived from the upper one by subtracting the amount of the freezing point depression; it represents the temperature that the ICB would have for the indicated depression.
Table 1 lists calculated values of $T_{m}$ at ICB pressure for the three crystal structures. Also shown are various thermodynamic parameters produced in the calculation. We note that for $\Delta \mathrm{V}_{\mathrm{m}}, \Delta \mathrm{S}_{\mathrm{m}}$, and $\mathrm{dT}_{\mathrm{m}} / \mathrm{dP}$ the temperature corrections cancel, and they are independent of freezing point depression. For comparison Verhoogen [9] calculated the latent heat of freezing to be $25 \cdot 10^{3} \mathrm{~J} / \mathrm{mole}$ using an entirely different approach.

Melting points of both closed-packed phases, whether or not there is a freezing point depression, do not differ significantly and are close to $6000 \mathrm{~K}$. The substantially lower melting point of the body centered cubic phase of $\mathrm{Fe}$ $(\approx 5600 \mathrm{~K})$ comes from a lower value of a geometric factor that expresses the effect of different crystallographic structures.

The agreement of $T_{m}$ for close-packed phases with the earlier value [1] is largely coincidental; it results from the fact that a slight numerical error in the value of the dilation caused by dislocations had cancelled the effect of not taking the pressure and the freezing point depression into account.

Melting temperature calculated for bcc iron agrees with the extrapolated value of Boehler [this volume] better than $T_{m}$ calculated for closepacked phases. Values for each phase match extrapclations from shock-wave experiments $\left(T_{m}\right.$ $\approx 5800 \pm 500 \mathrm{~K})[5]$ and with the estimation of Anderson [10] $\left(\mathrm{T}_{\mathrm{m}} \approx 6300 \mathrm{~K}\right)$. The temperature at the ICB directly depends on the unknown value of the freezing point depression. If the inner core is $\gamma$ or $\varepsilon$ iron, then for a depression of $1000 \mathrm{~K}$, the temperature of the ICB is close to $5000 \mathrm{~K}$, a value in agreement with the estimation of Spiliopoulos \& Stacey [11] and that of Brown \& McQueen [5]. The $\alpha^{\prime}$ phase requires less freezing point depression to achieve this temperature.

Table 1. Calculated thermodynamic parameters for iron phases at zero freezing point depression. Uncertainty is the standard deviation of the mean.

\begin{tabular}{llll}
\hline & e-iron, hcp & y-iron, fcc & a'-iron, bcc \\
\hline $\mathrm{T}_{\mathrm{m}}(\mathrm{Fe}), \mathrm{K}$ & $6160 \pm 250$ & $6060 \pm 260$ & $5610 \pm 240$ \\
$\mathrm{~T}_{\mathrm{icB}}, \mathrm{K}$ & $6160 \pm 2.50$ & $6060 \pm 260$ & $5610 \pm 240$ \\
Latent heat of freezing $=\mathrm{T}_{\mathrm{ICB}} \Delta \mathrm{S}_{\mathrm{m}}, \mathrm{J} / \mathrm{mole}$ & $40.0 \pm 1.9 \cdot 10^{3}$ & $39.3 \pm 2.0 \cdot 10^{3}$ & $36.2 \pm 1.8 \cdot 10^{3}$ \\
$\Delta \mathrm{V}_{\mathrm{m}}, \mathrm{cm}^{3} / \mathrm{mole}$ & $0.042 \pm 0.004$ & $0.041 \pm 0.004$ & $0.038 \pm 0.004$ \\
$\Delta \mathrm{S}_{\mathrm{m}}, \mathrm{J} \mathrm{mole}-1 \mathrm{~K}-1$ & $6.49 \pm 0.06$ & $6.49 \pm 0.06$ & $6.46 \pm 0.05$ \\
$\mathrm{dT}_{\mathrm{m}} / \mathrm{dP}, \mathrm{K} / \mathrm{GPa}$ & $6.46 \pm 0.59$ & $6.34 \pm 0.61$ & $5.88 \pm 0.57$ \\
\hline
\end{tabular}




\section{CONCLUSIONS}

The melting points of metals at ambient pressure calculated from the dislocation theory of melting agree well with observed values. We have used this theory as modified for high pressures to predict the melting poin of pure iron at the pressure of the inner core boundary. The calculation uses elastic moduli given by PREM for the inrer core at the ICB, corrected in temperature by an amount corresponding to possible freezing point depression of the outer core. If the iron of the inner core has a closepacked crystalline structure (hcp or fcc) its melting point is predicted to be close to $6000 \mathrm{~K}$; this value is an upper bound for the temperature at the ICB, which decreases as the freezing point depression increases and reaches $5000 \mathrm{~K}$ for a $1000 \mathrm{~K}$ depression. If, as recently suggested, the inner core were iron with the bcc structure, the melting point of this phase and the temperature at the ICB would be about $500 \mathrm{~K}$ lower than in the case of close-packed iron.

\section{ACKNOWLEDGMENTS}

TJS thanks the Institut de Physique du Globe de Paris and the Centre National de la Recherche Scientifique for support and hospitality. Portions of this work were performed under the auspices of the Office of Basic Energy Research, U.S. Department of Energy under contract W-7405ENG-36 with the University of California. This work was partly supported by CNRS (Unité de Recherches Associée 734).

\section{REFERENCES}

[1] J. P. Poirier, Geophys, J. R. Astr. Soc, 85, pp. 315 328 (1986).

[2] J. P. Poirier and G. D. Price, Phys. Earth Planet. Inter. 69, pp. 153-162 (1992).

[3] J. P. Poirier and T. J. Shankland, Geophys. J. R. Astr. Soc. in press (1993).

[4] O. L. Anderson, Phil. Trans. R. Soc. Lond. A 306, pp. 21 -35.(1982)

[5] J. M. Brown and R. G. McQueen, J. geophys. Res. 91, pp. 7485-7494 (1986).

[6] O. L. Anderson, Geophys. J. R. Astr. Soc. 84, pp. $561-579$ (1986).

17) R. Jeanloz, Annual Rev. Earth Planet. Sci. 18, pp. 357-386 (1990).
[8] M. Ross, D. A. Young, and R. Grover, J. geophys. Res. 95, pp. 21713-21716 (1990).

[9] J. Verhoogen, Energesics of the Earth, Washington, D.C.: National Academy of Sciences (1983).

[10] O. L. Anderson, J. Geomag. Geoelectr., in press (1993).

[11] S. Spiliopoulos and F. D. Stacey, J. Geodynamics 1, pp. $61-77$ (1984).

\section{DISCLAIMER}

This report was prepared as an account of work sponsored by an agency of the United States Government. Neither the United States Government nor any agency thereof, nor any of their employees, makes any warranty, express or implied, or assumes any legal liability or responsibility for the accuracy, completeness, or usefulness of any information, apparatus, product, or process disclosed, or represents that its use would not infringe privately owned rights. Reference herein to any specific commercial product, process, or service by trade name, trademark, manufacturer, or otherwise does not necessarily constitute or imply its endorsement, recommendation, or favoring by the United States Government or any agency thereof. The views and opinions of authors expressed herein do not necessarily state or reflect those of the United States Government or any agency thereof. 


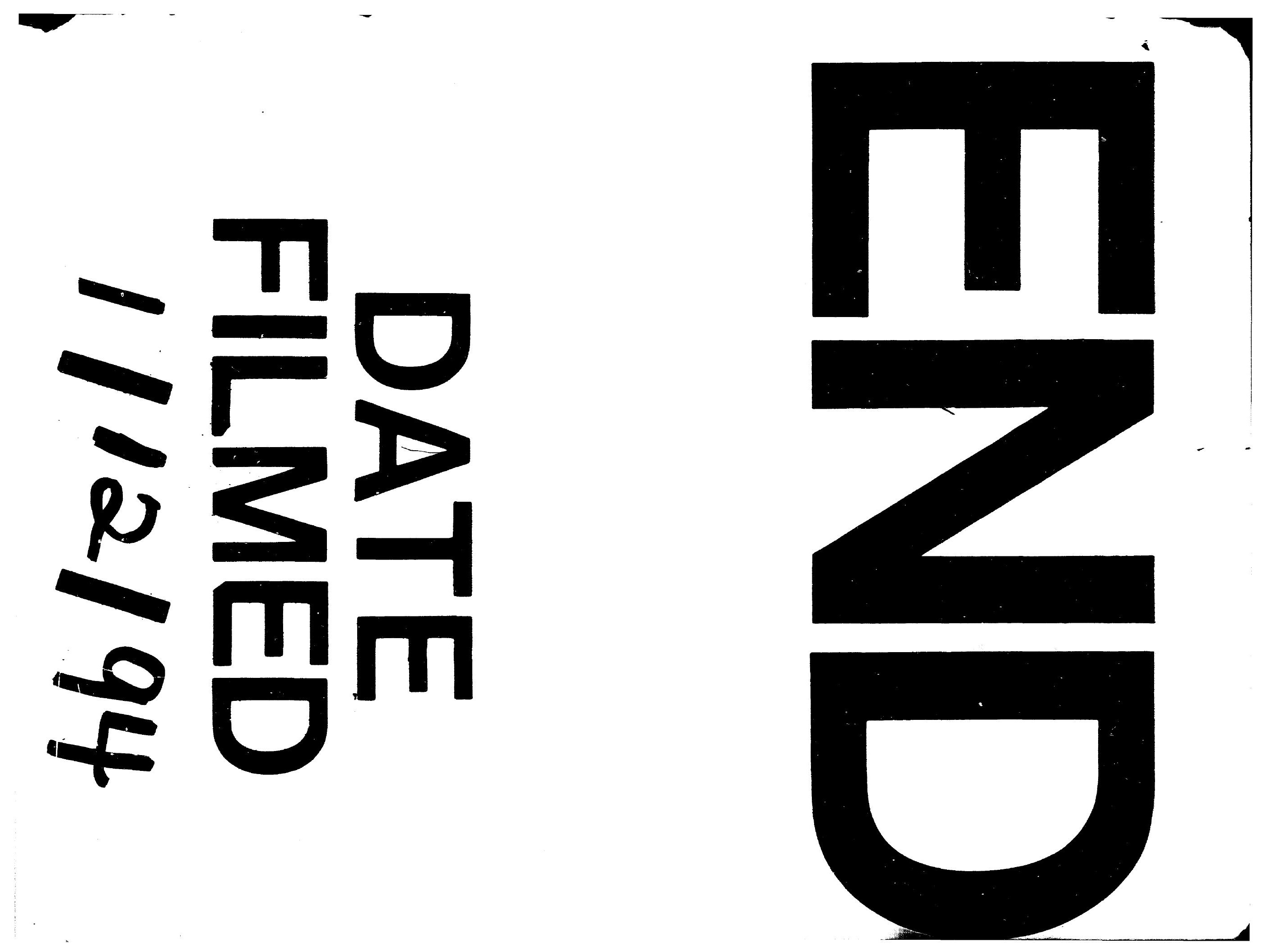


